\title{
Professionalism in Nursing
}

\author{
Siniša Franjic ${ }^{*}$
}

Independent Researcher

DOI: $10.36348 /$ sjnhc.2020.v03i09.001

| Received: 15.09.2020 | Accepted: 23.09.2020 | Published: 25.09.2020

*Corresponding author: Siniša Franjić

Abstract

Comparable with new scientific achievements in the field of medicine, the health care system is experiencing major structural changes that affect every segment and every profession directly or indirectly involved in the health care system. Nursing is a profession based on empathy and vocation, so as such it must adapt to modern medical and health knowledge. The development of the professional identity of nursing is a continuous process that begins with the acquisition of formal education in biomedicine, and continues to develop further through a professional career in a dynamic process in which there is an interaction of education and practical skills that ultimately leads to personal and professional growth and development.

Keywords: Nurses, Nursing, Health, Professionalism.

Copyright @ 2020: This is an open-access article distributed under the terms of the Creative Commons Attribution license which permits unrestricted use, distribution, and reproduction in any medium for non-commercial use (NonCommercial, or CC-BY-NC) provided the original author and source are credited.

\section{INTRODUCTION}

The relationship between professionals and clients has been the central feature of professional practice throughout history [1]. Professionalism has never been more important regarding public trust and care quality. The nature of professional practice in the community is particularly challenging given the complex care needs, diverse organisations and professions, as well as the need to demonstrate costeffective health outcomes. The relationship between service users and professionals is changing radically.

It is not easy to define precisely what a professional is or indeed what professionalism is - both concepts are fluid and contested areas. Traditionally, a professional is someone who is associated with being part of an elite group of experts with claims to specialist knowledge and skills that license their practice. The nature of the work is vocational, and like professional roles such as law and medicine, is valued within society. Professionals exercise their duty in the best interests of their clients and thereby their approach is intentionally altruistic. In that sense professionals may see themselves as the ideal advocates for their clients, being able to define their clients' needs and determine any solutions based on their expertise. Such attributes result in a high degree of professional autonomy and particular trusting relationships with their clients. In healthcare, licensed practitioners are permitted access to the human body in order to undertake intimate or intrusive assessments, clinical examinations and treatments. Thus, professionals have considerable power and higher moral standards are expected of professionals to do what is best for patients; this is enshrined in law as a duty of care owed to patients.

\section{Ethics and Practice}

Ethical principles and legal and policy frameworks direct the practice of all professionals [2]. In the community, it is important to understand these principles and be able to apply them in different situations as part of professional decision making. Values encompass personal, societal and professional domains and importantly influence practice. These values are socially constructed and thereby liable to change.

Professionals make decisions with or on behalf of others and need to have clear reasons to justify them. Being accountable is a key element of professional practice and clinical reasoning. Moral reasoning informs decisions, for example, whether or not to treat. A recent feature of professional practice has been the development of evidence-based practice, whereby decisions about treatment and care are neither subjective nor capricious. Using research evidence to underpin professional practice has come to be viewed as best practice, being both rigorous and objective following the scientific tradition. The standard by which professionals are judged is in relation to their peers makes the point that, 'The development of a more open 
and evidence-based approach to decision making in healthcare has shown how much personal values influence professional behaviour'. Referring to public health, he warns that science is far from being value free but that it is important to make values clear and decisions explicit.

There is a common set of principles that guides ethical practice in health and social care. Decisions are based not just on clinical evidence but also on a set of moral principles. Health itself is enshrined within human rights values. In order to do what is right in the particular circumstances, different stakeholders will have different views which need to be considered when making decisions. In the community, value-based decisions impact not only the service users but also their families and social networks and also their property, for example, the impact of converting a living room into a bedroom. Four ethical principles inform decision making in healthcare practice:

- Respect for autonomy

- Non-maleficence

- Beneficence

- Justice

\section{Professionalism}

Nursing is a clinical practice that includes systematic problem solving (the nursing process) and nursing management of identified patient needs [3]. In planning patient care, the nurse makes countless decisions concerning nursing diagnoses, construction and implementation of nursing care plans, and evaluation of patients' progress toward health. Each decision requires that the nurse combine a wide range of facts (or data) with a set of values to determine what ought to be done to help the patient fulfill his or her health needs. The facts are drawn from many different types of information about the patient: his or her medical and psychosocial histories, physiological status, economic status, and aesthetic and religious orientations. However, collection and analysis of the facts alone can never lead to a conclusion that a particular nursing intervention is morally justified. To reach a conclusion about what is morally justified in nursing practice, the nurse must combine relevant facts with a set of values. Thus, the first task in nursing ethics is to identify the many evaluations that take place in nursing practice and to separate the moral from the nonmoral components in these evaluations.

Healthcare is knowledge-intensive work [4]. Whether it is for treatment, rehabilitation or palliation, meeting patients' needs is an intellectually intricate activity involving numerous individuals with discrete expertise. Not surprisingly, then, knowledge management is a central preoccupation of hospital organisation with significant resources committed to accumulating, documenting and sharing information. Despite such investment, for the purposes of ongoing patient care much of the day-to-day work of knowledge generation is undertaken by nurses and while it may be true that no single individual possesses complete understanding of specific patients, nurses come closest to holding this global view.

\section{Community Nursing}

Community health nursing focuses on preventing illness and improving the health of populations and communities [5]. Population is defined as a group of people who may or may not interact with each other within a defined geographical location. Community health nurses work in geographically and culturally diverse settings. They address current and potential health needs of the population or community. They promote and preserve the health of a population and are not limited to particular age groups or diagnoses. Public health nursing is a specialized area of community health nursing.

In the past, the only community-based roles for nurses were community health nurses or public health nurses. This is now a subset of what is considered communitybased nursing. The health needs of the society and consumer demand brought about community-based and community-focused services. The movement from an illness-oriented "cure" perspective in hospitals to a focus on health promotion and primary health care in community-based settings has dramatically changed employment opportunities for today's nurses. This shift in emphasis to primary care and outpatient treatment and management will likely continue. As a result, employment growth in a variety of community-based settings can be expected for properly educated nurses.

Nursing interventions involve any treatment that the nurse performs to enhance the client's outcome. Nursing practice in the community uses the nursing process and is similar to that in the acute care setting, because assessing, performing procedures, administering medications, coordinating services and equipment, counseling clients and their families, and teaching about care are all part of the care administered by nurses in the community.

\section{Mental Health}

Nurses and other health care professionals form a core component of many health care systems so their roles in responding to the challenges set by the increase in the use of psychoactive substance use are crucial [2]. Nurses in both primary health care and residential settings are usually the first point of contact with many who misuse alcohol and drugs. Nurses are often reluctant to work with alcohol and drug misusers, mainly because of anxieties concerning role adequacy, legitimacy and lack of support. 
Nurses have a shared set of values, which find their expression in The Code: standards of conduct, performance and ethics for nurses and midwives. Nurses have the following responsibilities:

- To make the care of people their first concern, treating them as individuals and respecting their dignity.

- To work with others to protect and promote the health and wellbeing of those in their care, the patients' families and carers, and the wider community.

- To provide a high standard of practice and care at all times.

- To be open and honest, act with integrity and uphold the reputation of their profession.

Alcohol and drug misusers must be able to trust nurses with their health and wellbeing. The Code also states that 'as a professional, you are personally accountable for actions and omissions in your practice and must always be able to justify your decisions' and that 'you must always act lawfully, whether those laws relate to your professional practice or personal life'. Those with early substance use problems, chronic problem drinkers and drug users have the same rights vis-à-vis other patients in receiving appropriate health care from the National Health Service (NHS). Every member of the health care profession has an important role to play in responding to substance misuse problems.

Given the extent and nature of the normalisation of psychoactive substances in society, only a minority of drug and alcohol misusers is likely to come into contact with specialist drug and alcohol agencies. Most of them will invariably have first contact with primary care services, medical and psychiatric services, social services and voluntary agencies, and the criminal justice system. The need for the management and treatment of substance misuse problems is no longer confined to the specialist services. Nurses, in different specialities and settings, are also likely to come into contact with alcohol and drug misusers.

\section{Consent}

A patient has a right to withhold consent for examination or treatment, or withdraw it at any time [6]. Consent is important in the law because of its connection with trespass to the person, that is, assault or battery. An assault is any act which causes in the person subjected to it an apprehension of the immediate infliction of a battery. A battery is the physical contact with another's person. To have obtained informed consent is a defence against an accusation of assault and/or battery.

Consent may be express, when it is oral or written down, and this is the usual practice for surgical procedures. It is implied, for example in compliant actions such as raising one's arm for an injection. Implied consent may be adequate for minor procedures.

The most important element in consent is the patient's understanding of what is going to be done. Obtaining valid consent involves giving an explanation of the nature of the examination or treatment, of any substantial risks involved, of any side-effects and consequences for the life of the patient, mentioning alternatives, and giving all this information in a form which is comprehensible to the patient. Of course, the patient may be advised about a course of action, but it is important to back up this advice with the reasons.

\section{Confidentiality}

A health record contains information related to a person's health, which includes both physical and mental aspects [7]. As part of the common law duty of care to the patient the nurse must ensure that any information that identifies a patient, which comes into their hands in the course of their employment, is safeguarded and remains confidential. In a therapeutic relationship, common law as well as legislation also requires a duty of confidentiality stating that, "patient information may not be passed on to others without the patient's consent except as permitted under Schedules 2 and 3 of the Data Protection Act 1998, or where applicable, under the commonlaw where there is an overriding public interest'. Healthcare providers have a duty of care in ethics and in law to respect this confidentiality. Furthermore, from an ethical perspective this is not an unreasonable expectation in a fiduciary (Trust). It is also important that healthcare professionals who have access to information that may identify a patient maintain this trust-based relationship by sustaining confidentiality.

\section{Forensic Nursing}

Family violence, in all its forms, is a crime in every state in the United States [8]. Regardless of whether it is child abuse, dating violence, intimate partner violence, elder abuse, or the abuse of vulnerable people with cognitive, mental health, or physical disabilities, it is a crime to push, slap, punch, kick, or injure anyone. Many forms of familial or institutional neglect are also potentially criminal in nature. Nurses encounter individuals who have experienced family violence. Some of these acts of violence may be investigated by law enforcement.

Forensic nurses address health care issues with a legal component. Forensic practice is part of holistic care by adding the legal issues that surround victims, perpetrators, and their families and significant others. Forensics pertains to the law and the courts; however, it is not limited to the criminal courts. While not every nurse is a trained forensic nurse, many nurses routinely encounter forensic issues in their practices. Nurses who work with survivors of family violence throughout the life cycle may be asked to collect evidence for and 
testify in a variety of courts, including criminal, family, guardianship, juvenile, and probate courts.

The role of the forensic nurse includes three broad areas: (1) provide thorough, competent, and compassionate care to patients who have experienced violence; (2) collect evidence and document findings in a manner that that allows for the use of the evidence and findings in the investigation and adjudication of a criminal case; and (3) testify about the facts of the case and as an expert. To some extent, these aspects of the forensic role can be in conflict with each other. For example, the nurse's role as patient advocate could impair the nurse's ability to provide unbiased testimony in a criminal trial. Forensic nurses can best address the possibility of conflict in these roles by providing highquality, patient-centered care and remaining as objective as possible. Forensic nurses should not think of themselves as "victim advocates" and should refer to the person for whom they are providing care as a patient, not a victim or survivor of violence. Competent nursing care always requires that nurses act in the best interests of their patients (not just forensic patients), so serving as a patient advocate does not present any conflict with other aspects of the nurses' role. Nurses must collect evidence with the knowledge that this evidence will serve the criminal justice system, not just the prosecutors, remaining as objective and neutral as possible in their handling of the evidence and documentation of the findings. Finally, forensic nurses with a history of providing objective testimony in court, whether their testimony benefits the prosecution or defense in a particular case, will be seen as more credible than nurses biased in favor of the prosecution. Carefully objective, thoughtful forensic nursing care at all stages will ultimately provide the greatest benefit to survivors of violence.

\section{Telenursing}

Nursing is nursing whether practiced in the face-to-face setting or over the phone [9]. The ability to provide care over the telephone has opened a new frontier through which nursing care can be delivered. The telephone and other forms of telecommunications technology provide access to information and advice from nurses, allow for improved communication, and enable nurses to more fully involve, support, and assist patients in making informed health care decisions. Standards exist, however, that must be incorporated into this new form of nursing care delivery. It is imperative that telephone triage nurses and other health care professionals such as physicians and administrators realize these encounters are not "just another phone call." Rather, they represent professional nursing practice.

Telephone triage is an integral element of ambulatory care nursing. In fact, telehealth nursing practice is one of the defining characteristics of the ambulatory care specialty. Continuing education and training are available to nurses interested in developing the expertise and specialized skill set necessary for telephone triage. Despite the fact that more than $25 \%$ of the RNs (Registered Nurses) in the United States practice in ambulatory care, neither ambulatory care nursing nor telehealth nursing is presently included in basic nursing curricula. Although one can become certified in ambulatory care nursing and thus recognized as having specialty expertise, practice in this area requires and builds upon basic nursing education. As will become clear throughout the course of this book, skills and experience beyond basic nursing education, as it currently exists, are required for competent practice in telephone triage.

Nursing standards and scope of practice define the minimum expectations for nursing practice and may be used as objective (legal and professional) guidelines for nursing performance. The American Nurses Association (ANA) has written the standards and scope of practice for professional nursing. The scope of practice for all nurses is defined and regulated by state boards of nursing through nurse practice acts and related policies. For matters of common interest and concern, these state boards act and counsel collaboratively through the leadership of the National Council of State Boards of Nursing (NCSBN).

\section{Nurses and Other Health Professionals}

As well as keeping up with new knowledge and with changes in the health system and organisations they are working within, nurses and other healthcare professionals are taking up more and more different roles [10]. Roles change as professionals expand existing roles. This often means that other staff are required to take on some aspects of a previous role, for example as registered nurses expand their role, healthcare support staff often take on elements of basic care which were previously part of the registered nurse role. Healthcare professionals may develop new roles which are designed to fit within their scope of practice, for example new clinical nurse specialist roles and emergency nurse practitioner roles. Such roles are an extension of professional practice for an individual group, although in some circumstances another professional group may feel that the role is equally appropriate for them. Completely new roles may be developed which do not fit existing professional boundaries, for example healthcare support staff who work between nursing, physiotherapy and occupational therapy. These roles can be filled by existing healthcare staff or by staff new to the health service with appropriate training and education.

Embedding patient perspectives in all areas of health and social care is a safeguard against the escalation of paternalistic and unquestioned professional practices. But rather than just helping to keep professionals working in a professional way, service user involvement can also be a source of 
inspiration for new forms of professionalism. For example, service user involvement in research extends professional accountability to the public beyond reporting research findings, towards a greater awareness of the need to 'translate' research on behalf of service users in terms of the language, focus and priorities of those research is intended to serve. The developing role of nurses and healthcare professionals requires them not only to understand research findings and to weigh-up different forms of evidence, but to generate new evidence in partnership with service users. As part of their professional role, nurse and healthcare researchers can learn about indicators of successful involvement, how to document service user involvement work, and how to make use of reflective techniques to build towards quality experiences of involvement and quality environments for involvement.

\section{CONCLUSION}

The needs of health care users (individual, family, community) have become, thanks to modern scientific knowledge in the field of biomedicine, much more complex, so nurses must achieve a higher level of skills, competencies and attitudes to meet these needs for quality, safety and efficiency way. Increasing the share of the population aged 65 or over who becomes the primary beneficiary of all types of health care and nursing, increasingly complex forms of disease, chronic diseases, introduction of new, more demanding methods and procedures in health care, community education, palliative care, gerontology centers, work in the educational system and in public health programs they speak in favor of a wide range of actions of the nurses. Therefore, there is a need to increase the level of education. In the academic community, it is continuously necessary to find new opportunities and accept new guidelines in order to increase the level of quality of health care and continuing education programs for nurses.

\section{REFERENCES}

1. Skinner, J. (2018). Professional approaches to care“ in Chilton, S.; Bain, H. (eds): „A Textbook of Community Nursing, Second Edition“, Routledge, Taylor \& Francis Group, New York, USA, 45-51.

2. Rassool, G. H. (2010). Addiction for Nurses“, Wiley-Blackwell, John Wiley \& Sons Ltd, Chichester, UK, 1-2.

3. Fry, S. T., Veatch, R. M. Taylor, C. (2011). Case Studies in Nursing Ethics, Fourth Edition“, Jones \& Bartlett Learning, LLC, Sudbury, USA, 3.

4. Allen, D. (2015). The Invisible Work of Nurses Hospitals, Organisation and Healthcare“, Routledge, Taylor \& Francis Group, Abingdon, UK, 30.

5. Ricci, S. S. (2009). Essentials of Maternity, Newborn, and Women's Health Nursing, Second Edition“, Wolters Kluwer Health, Lippincott Williams \& Wilkins, Philadelphia, USA, 25-26.

6. Taplin, D. (1994). Nursing and informed consent: An empirical study" in Hunt, G. (ed): Ethical Issues in Nursing - Professional Ethics“, Routledge, Taylor \& Francis Group, New York, USA, 22.

7. Buka, P. (2008). Patients' Rights, Law and Ethics for Nurses - A Practical Guide“, Hodder Arnold, London, UK, 54.

8. Laughon, K., Amar, A. F., Sheridan, D. J., Anderson, S. (2011). Legal and Forensic Nursing Responses to Family Violence“" in Humphreys, J.; Campbell, J. C. (eds): „Family Violence and Nursing Practice, Second Edition“, Springer Publishing Company, LLC, New York, USA, 367368.

9. Rutenberg, C., Greenberg, M. E. (2012). The Art and Science of Telephone Triage - How to Practice Nursing Over the Phone“, Telephone Triage Consulting, Inc., Pitman, USA, 61-63.

10. Morrow, E, Boaz, A., Brearley, S., Ross, F. (2012). Handbook of Service User Involvement in Nursing and Healthcare Research“, Wiley-Blackwell, John Wiley \& Sons, Ltd, Chichester, UK, 184-185. 